\title{
Determining Factors Responsible in Shifting Consumption of Mobile Data (2G to $3 G$ )
}

\author{
Arshad Khan \\ Dept: Computer science \\ Qurtuba University Peshawar
}

\author{
Sarfaraz Javed, PhD \\ Department of Commerce, \\ Aligarh Muslim University, Aligarh
}

\begin{abstract}
This study is about the Influential elements that have been inquire into by the researcher which induce them to change their mind to shift from $2 \mathrm{G}$ to $3 \mathrm{G}$ mobile technologies in Dera Ismail Khan and this is the main goal of this research. Those factors are also address in the research questions of this study that influence the users of mobile phone to shift to $3 \mathrm{G}$ mobile technology. This study have been derived from the earlier research and tried to discover the gap in the previous studies. To analyze the interval of the started subjects was the main goal of this subject not in reference to Dera Ismail Khan but in reference to Pakistan. With 200 sample of respondents who take part in the study and Quantitative research method was used in this study. The source of data assimilation was the university students in Dera Ismail Khan. Reliability was approved by the reliability of the sample data and we can analyze the data again by this reliability, and on collected sample Chi square test was used reliability test, which display $79.8 \%$ which exhibit the. The conclusion of the study reveals
\end{abstract}

that this technology is not adapted by the users of the $3 \mathrm{G}$ technology and respondents in reference to Dera Ismail Khan.

\section{Keywords}

Chi Square, 2G Technology, 3G Technology, Influential factors,. Reliability Test

\section{INTRODUCTION}

$3 \mathrm{G}$ is a third generation terminology which is utilized to define cellular services and mobile networking and as compared to the users of $1 \mathrm{G}$ (first generation) and $2 \mathrm{G}$ (second generation), it propose higher speed. In vehicles the rate of $3 \mathrm{G}$ data is $144 \mathrm{Kbps}$ for cellular users in vehicles, and $384 \mathrm{Kbps}$ for pedestrian users and 2 Mbps speed for fixed location [1]. The working of 3G started from 2006 in comparison to the services of $1 \mathrm{G}$ and $2 \mathrm{G}$ which arrived 1940s and 1990s respectively and increase the speed from 10 to $20 \mathrm{Kbps}$ respectively.

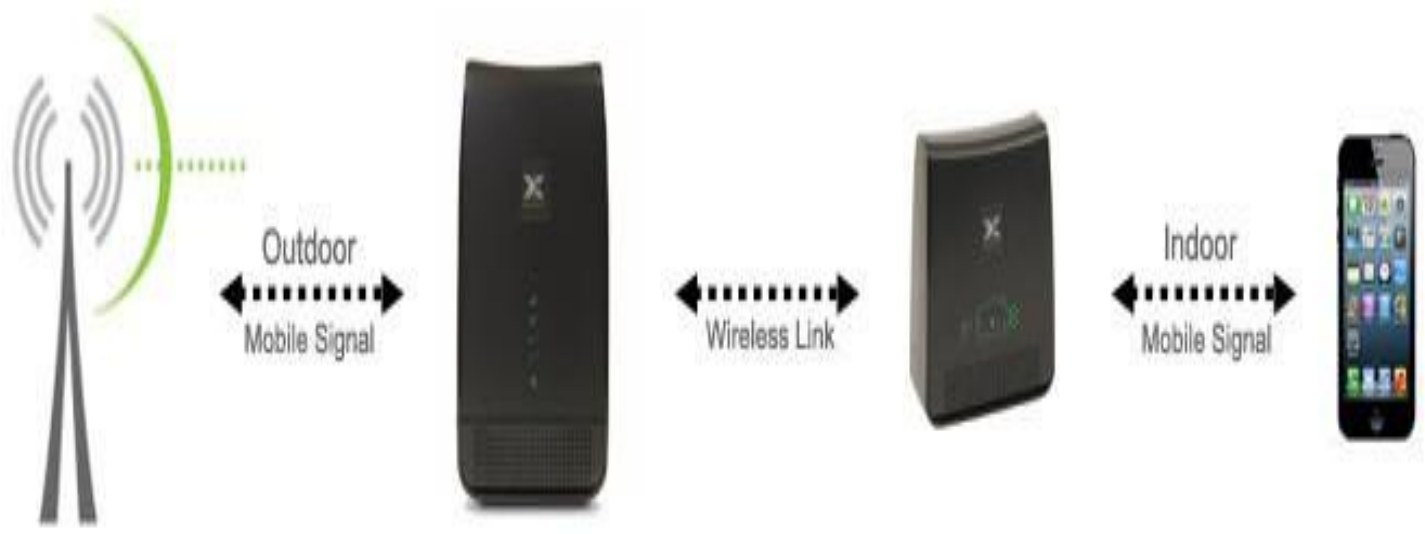

Figure-1 How 3G works with mobile phone

Ahmed Rizwan et al (2014)

For SMS (short messaging services) and voice conversation 3G can be utilized [2]. In top $53 \mathrm{G}$ technology growing countries like Japan, Italy, Korea, and Hong Kong. it is perceived that gradually it is growing. It can be determine by the report of this $3 \mathrm{G}$ technology growing countries that the largest perceptive country is Korea among the top 5 with the rate of $25.95 \%$ and the report also reveal that in Asian regions $3 \mathrm{G}$ subscribers are also close to the half of those $53 \mathrm{G}$ technology growing countries.[3].

In Pakistan the services of the cellular phone are developing regularly and the improvement of the technology is a useful extension. Products are provided according to the demands of their users by service providers. In Pakistan the study of the $3 \mathrm{G}$ technology is very significant in order to conceive the concern and needs of the users for the employment of this technology because its desire of using is increasing rapidly.

The major aim of this research is to know those elements which cause them to divert from $2 \mathrm{G}$ to $3 \mathrm{G}$ technology in Dera Ismail Khan. In reference to $3 \mathrm{G}$ technology various researches have been made. The result of which shows that with the usage of this service the recognized quality of $3 \mathrm{G}$ technology is important while the other studies shows no particular relationship in their result between the payment and the gender type with $3 \mathrm{G}$ technologies[4]. There are also other 
elements which influence them to choose $3 \mathrm{G}$ networks that is celebrity endorsement [5]. But with reference to Pakistan this type of research has been conducted. For that reason such type of studies should be made to fill that space.

$\mathrm{Zu}$ et.al [6] inquired into to analyze that in the service of the users 3G technology is a significant inclusion. The study was organized on residents of China. In their organizations China have utilized a technology having 9 significant elements called Technology Acceptance Model (TAM) which is appealing for the customers to use 3G technology in their organization. Through questionnaire sample data was assimilated in a big extent and SPSS software has been utilized for factor analysis in this study for residents of China and the result of which reveals that the significant factors in usage of $3 \mathrm{G}$ technology are the social impact and security. The study also constitutes gender wise factors. Male as compared to female, as an element of enjoyment consonance prefers $3 \mathrm{G}$ although female give preference to the efficiency and expenditure.

Casal et.al [7] Determine the aspects other than 3G technologies. The researchers regulate that study in Europe and have applied the approach concerned with quality. Various $3 \mathrm{G}$ technology users were interviewed by them. The conclusion of the study reveals that European users are not admirable at $3 \mathrm{G}$ but they are more fascinated towards $3 \mathrm{G}$ so they should not criticize by the service provider.

Harno, J. [8] Inquire into the analysis which is above the $3 \mathrm{G}$ and its substitute called techno economic analysis. This study was executed on quantitative approach by adopting the aspect of income and expenditure supported by GSM, EDGE and GPRS. On concluding the study it reveals that the approach to use the procedure of Wi-max and UMTS are profitable for business while to bring about profits from the business large drivers of UMTS are more affective.

Lee et.at [9] by using the method of case study at market economy in Romania ascertains that the cellular industry have hand in economic development. It has been derived from the study that for the attaining the absolute and consequential results cellular service provider should pay attention on the basic services. The Martin [10] study also shows improvement in the duty and adjournment in services.

Saugstrup and Henten [11] with reference to $3 \mathrm{G}$ paradigm evaluate the contest between the CDMA and WCDMA. For this study they have employed qualitative approach and inspected the operators, policies, ultimate consumers and appliances of the technology. For $3 \mathrm{G}$ and also for the supremacy of market share this technology is very effective.
This research in the conclusion preferred WCDMA technology instead of CDMA.

\section{METHODOLOGY}

\subsection{Research approach}

Quantitative approach is the basic method of the research. To conceive the attitude of users and for utility of numbers this method is utilized so that they accept $3 \mathrm{G}$ technologies.

\subsection{Tool for obtaining data}

The tool for data collection in this study id sample questionnaire which contains on the scales of five point likert and for obtaining data such questionnaire is handed out to the people.

\subsection{Target population}

The university students of Dera Ismail Khan are the target population of this research who are expected as the first factor for the acceptance of $3 \mathrm{G}$ services.

\subsection{Size of the sample}

With a view to attain the feedback for acceptance of $3 \mathrm{G}$ technology 200 questionnaire were given away to the target population.

\subsection{Sampling technique}

In this study convenience sampling technique has been used. This technique is used because geographical necessity is the condition of the study.

\subsection{Statistical technique}

Chi-square is the statistical research technique used in this study. When you have single categorical variable from a single population chi-square is implemented. It is utilized to ascertain either sample data are compatible with a hypothesized handing outs.

\subsection{Research design}

Correlation research design is the design of the research. As the study was carried to analyze correlation between motivational elements and attitude of the users for accepting $3 \mathrm{G}$ technologies.

\section{RESULTS AND DISCUSSION}

\subsection{Data analysis}

We have analyzed the data in this part of the study which was gathered with the help of questionnaire. For ascertaining results from the accumulated data SPSS 20 software has been used.

Table 1 Reliability Test

\begin{tabular}{|l|c|}
\hline \multicolumn{2}{|c|}{ Reliability Statistics } \\
\hline Cronbach's Alpha & No of Items \\
\hline 0.789 & 10 \\
\hline
\end{tabular}


Table 2 Model Frequency

\begin{tabular}{|c|c|c|}
\hline \multicolumn{3}{|c|}{ Model Frequency } \\
\hline Variable & Frequency & Percentage \\
\hline AVAILABILITY & 43 & $36 \%$ \\
\hline SPEED & 38 & $32 \%$ \\
\hline Voice Quality & 50 & $42 \%$ \\
\hline Video Quality & 43 & $36 \%$ \\
\hline Verity of Service & 48 & $40 \%$ \\
\hline
\end{tabular}

Table 3 Chi Square

\begin{tabular}{|l|c|l|l|}
\hline \multicolumn{4}{|l|}{ Chi Square } \\
\hline Pairs & Chi-Square & Signal & Result \\
\hline AGE & 24.941 & 0.353 & ACCEPTED \\
\hline Gender & 99.171 & 0.286 & ACCEPTED \\
\hline INSTITUTE & 61.48 & 0.728 & ACCEPTED \\
\hline PROGRAM & 107.593 & 0.127 & ACCEPTED \\
\hline YEAR OF PROGRAM & 83.556 & 0.112 & ACCEPTED \\
\hline
\end{tabular}

\subsection{Reliability Test (Cronbach's Test)}

To analyze the reliability of the accumulated data reliability test has been used. When the data is assimilated by means of principal sources this test is mostly utilized at that time. Chronbach's alpha value is a substantial parameter which is used to test the reliability of the data. This value must be 0.7 or $70 \%$ or above. The authenticity of data depends upon this value. If the values go beyond $70 \%$ we would have more authentic data.[18] The data we have accumulated in this study is adequate to carry out other investigations because the value of chronbach's alpha is $0.789 \%$ in this case.

\subsection{Frequencies Tabulation}

Frequency distribution of the model has been mentioned in the table above. At the beginning before the assimilation and evaluation of data its structure was unorganized; variables data is transformed into organized structure. For using $3 \mathrm{G}$ technologies the most adopted variable is shown in the above table. The most suggested variables are Availability, speed, voice quality, video quality, and variety of service with $36 \%$, $32 \%, 42 \%, 36 \%$ and $40 \%$ respectively.

\subsection{Chi Square Test}

The chi square values depend upon the real and calculated result which has been mentioned in the above table. The difference between the real and calculated data shows that chi square value will be larger but chi square value will be smaller when difference between the real and calculated data is lower. Hence the larger or greater value of the chi square shows that there is a possibility of importance of the difference. In our study the there is an expressive dissimilarity between acceptance of $3 \mathrm{G}$ technology and the sample of our respondents because of the value of the chi square of all the variables which is larger than critical value. So to conclude on basis of study result we can say that this technology in our sample is not accepted by our respondents and 3G technology consumers

\section{CONCLUSION}

This study is about the influential elements that have been inquire into by the researcher which induce them to change their mind to switch from $2 \mathrm{G}$ to $3 \mathrm{G}$ technologies in Dera Ismail Khan and this is the main goal of this research. Those factors are also address in the research questions of this study that influence the users of mobile data users ( students) to shift to $3 \mathrm{G}$ technology. This study have been derived from the earlier research and tried to discover the interval between the researches. To analyze the interval of the already started subjects was the main goal of this subject not in reference to Dera Ismail Khan but in reference to Pakistan. With 181 sample of respondents who take part in the study and computable research method was used in this study. The source of data assimilation was the university students in Dera Ismail Khan. Reliability was approved by the reliability test, which display $79.8 \%$ which exhibit the reliability of the sample data and we can analyze the data again by this reliability, and on assembled sample Chi square test was employed. The conclusion of the study reveal that this technology is not adapted by the users of the $3 \mathrm{G}$ technology and respondents in reference to Dera Ismail Khan. In Pakistan the services of the cellular phone are developing regularly and the improvement of the technology is a useful extension. Products are provided according to the demands of their users by service providers. In Pakistan the study of the $3 \mathrm{G}$ technology is very significant in order to conceive the concern and needs of the users for the employment of this technology because its desire of using is increasing rapidly.

\section{RECOMMENDATIONS}

The recommendations depends upon the consequences derived from the assimilated data: i. In university students to accept $3 \mathrm{G}$ technology is not their common priority so the service supplier should concentrate to make purposeful 
expansion in the services to draw their attention. ii. 3G technology among the teenagers is also not acceptable so the considerable efforts should be made to fascinate them. iii. The cash flow of the company can be effect by the proficient because they are interested in accepting technology but this is distressing conditions that they also refused to use it in our study because the people of this category can grow the income of the company so $3 \mathrm{G}$ technology service providers should pay attention to this field.

\section{REFERENCES}

[1] Peha J. and Satapathy D., Spectrum sharing withoutlicenses: Opportunities and Dangers. In G. Rosston and D.Waterman (Eds.), Interconnection and the Internet: Selected papers from the 1996 telecommunicationsresearch (1997)

[2] William Lehr, and Lee W McKnight, Wireless Internet Access: 3G vs. Wi-Fi? Telecommunication Policy, 27 (5), 351-370 (2003)

[3] International Union of Telecommunication, Resolution 25Rev. Plenipotentiary Conference, Antalya (2006)

[4] Mardikyan S., Besiroglu B. and Uzmaya G., BehavioralIntention towards the Use of $3 \mathrm{G}$ Technology,Communications of the IBIMA, 10 (2012)

[5] Noam E., The next frontier for openness: Wireless communications. Draft paper presented at 2001, Telecommunications Policy Research Conference,Alexandria, VA, October (2001)

[6] Du H., Zhu G., Zhao L. and Lv. T., An empirical study of consumer adoption on $3 \mathrm{G}$ value-added services in China,Emerald Research journal, 3(3), 257-283 (2012)

[7] Casal C.R., Burgelman F.C. and Bohlin E., Prospects beyond 3E, Emerald Research Journal, 6(6), 359-362 (2004)

[8] Harno J., Techno-economic analysis of beyond 3G mobile technology alternatives, Emerald Research Journal, 11 (3), 45-63 (2009)
[9] Lee S., Sylvia M. Chan-Olmsted and Kim, H., the Deployment of Third-Generation Mobile Services, 1-32 (2009)

[10] Martin M., Verizon wireless gets closer to 3G. NetworkWorld, February 4 (2002)

[11] Dan Saugstrup, Anders Henten, 3G Standards: the battleBetween WCDMA and CDMA 2000, info, 8 (4), 10-20(2006)

[12] Mahdi Safaa A., Muhsin Asaad H. and Al-Mosawi Ali I, Using Ultrasonic Sensor for Blind and Deaf persons Combines Voice Alert and Vibration Properties, Research Journal of Recent Sciences, 1(11), 50-52 (2012)

[13] Seena Abraham, Quality of life Among Adolescents with Physical Disability Undergoing Integrated Education,Research Journal of Social Sciences, 2(5), 1-5 (2013)

[14] Eskandar J., Intellectual Capital and its Effects on Firms'market value and Financial Performance in Iran: An Investigating Public Model, Research Journal of Recent Sciences, 2(3), 1-6 (2013)

[15] Mangang P.N., Health Beliefs and Perception of Wellbeing among the Lois of Thanga in Manipur, India, Research Journal of Recent Sciences, 1(4), 46-52 (2012)

[16] Nwajei G.E., Okwagi P., Nwajei R.I. and Obi-Iyeke G.E.,Analytical Assessment of Trace Elements in Soils, TomatoLeaves and Fruits in the Vicinity of Paint Industry,Nigeria, Research Journal of Recent Sciences, 1(4), 22-26 (2012)

[17] Ahmed Rizwan Raheem, Ahmad Nawaz, Mirza Mujeeb, Khoso Imamuddin 2 and Parmar Vishnu. (2014). Factors that Motivate the Mobile Phone Users to switch from $2 G$ to $3 G$ Technologies in Karachi. Research Journal of Management Sciences .Vol. 3(8), 18-21,

[18] sekaran, U. (1999). Research methods for business: A skill-building approach. 3rd ed. John 